\title{
Long-term persistence with anti-osteoporosis drugs after fracture
}

\author{
C. Klop • P. M. J. Welsing • P. J. M. Elders • J. A. Overbeek • \\ P. C. Souverein - A. M. Burden • H. A. W. van Onzenoort • \\ H. G. M. Leufkens • J. W. J. Bijlsma • F. de Vries
}

Received: 19 October 2014 / Accepted: 19 February 2015 / Published online: 31 March 2015

(C) The Author(s) 2015. This article is published with open access at Springerlink.com

\begin{abstract}
Summary Long-term persistence with anti-osteoporosis drugs and determinants for discontinuation among fracture patients were examined. Persistence was 75.0 and $45.3 \%$ after 1 and 5 years, respectively. Those aged $\geq 80$ years were at increased risk of early discontinuation. Within 1 year after discontinuation, $24.3 \%$ restarted therapy, yet $47.0 \%$ persisted for 1 year. Introduction The risk of osteoporotic fracture can effectively be reduced with use of anti-osteoporosis drugs. However, little is known about persistence with these drugs after fracture where subsequent fracture risk is high. The aims were to determine long-term persistence with anti-osteoporosis drugs among fracture patients, including its determinants, and to describe restart and subsequent persistence.
\end{abstract}

Electronic supplementary material The online version of this article (doi:10.1007/s00198-015-3084-3) contains supplementary material, which is available to authorized users.

C. Klop • P. C. Souverein · A. M. Burden · H. G. M. Leufkens •

F. de Vries $(\triangle)$

Utrecht Institute for Pharmaceutical Sciences, Division of

Pharmacoepidemiology and Clinical Pharmacology, Utrecht

University, Utrecht, Netherlands

e-mail: f.devries@uu.nl

P. M. J. Welsing • J. W. J. Bijlsma

Department of Rheumatology and Clinical Immunology,

University Medical Center, Utrecht, Netherlands

P. M. J. Welsing

Julius Center for Health Sciences and Primary Care,

University Medical Center, Utrecht, Netherlands

P. J. M. Elders

Department of General Practice and Elderly Care, VU University

Medical Centre, Amsterdam, Netherlands
Methods A cohort study was conducted within the Dutch PHARMO Database Network. Patients aged $\geq 50$ years $(n=961)$ who received anti-osteoporosis drugs within 1 year after fracture, but not in the preceding year, were included (2002-2011). Persistence (defined as the proportion on treatment) and the proportion restarting after discontinuation were estimated using Kaplan-Meier analyses. Time-dependent Cox regression was used to identify determinants of non-persistence including age, sex, initial dosage regime, fracture type, comorbidities, and drug use.

Results Persistence with anti-osteoporosis drugs was $75.0 \%$ (95\% confidence interval (CI) 72.0-77.7) and $45.3 \%(95 \%$ CI 40.4-50.0) after 1 and 5 years, respectively. A significant determinant of non-persistence was age $\geq 80$ years (reference

J. A. Overbeek

PHARMO Institute for Drug Outcomes Research, Utrecht, Netherlands

A. M. Burden $\cdot$ H. A. W. van Onzenoort $\cdot$ F. de Vries Department of Clinical Pharmacy and Toxicology, Maastricht University Medical Centre+, Maastricht, Netherlands

F. de Vries

MRC Lifecourse Epidemiology Unit, Southampton General Hospital, Southampton, UK

H. A. W. van Onzenoort Department of Pharmacy, Radboud University Nijmegen Medical Centre, Nijmegen, Netherlands 
50-59 years: adjusted hazard ratio [adj. HR] 1.65; $95 \%$ CI $1.15-2.38)$. This effect was not constant over time ( $\leq 360$ days following initiation: adj. HR 2.07; $95 \%$ CI 1.27-3.37; $>360$ days: adj. HR 1.08; $95 \%$ CI 0.62-1.88). Within 1 year after discontinuation, $24.3 \%$ (95\% CI 20.1-29.2) restarted therapy, yet $47.0 \%$ persisted for 1 year.

Conclusions This study identified suboptimal persistence with anti-osteoporosis drugs among fracture patients. Major target groups for measures aimed to improve persistence may be those aged $>80$ years and those restarting therapy.

Keywords Epidemiology $\cdot$ Fracture prevention .

Osteoporosis $\cdot$ Persistence $\cdot$ Therapeutics

\section{Introduction}

Osteoporotic fractures are a major burden for the patient in terms of increased morbidity, mortality, and a reduction in quality of life [1]. Prior fractures are strong predictors of fracture risk. Indeed, the fracture risk is two-fold higher following a non-vertebral fracture and is quadrupled after a vertebral fracture [2]. This risk is not constant over time with a fivefold higher risk in the year after the first fracture followed by a gradual waning off [3]. Within 5 years after the initial fracture, up to one third of the patients will sustain a new fracture $[4,5]$.

Anti-osteoporosis drugs, of which bisphosphonates are the most commonly prescribed, have shown to reduce the relative risk of osteoporotic fractures by $20-70 \%$ in clinical trials, depending on the drug and fracture type [6-8]. Persistence with therapy is an important determinant for the anti-fracture efficacy of anti-osteoporosis drugs in clinical practice [9-12]. A meta-analysis with data of 219,676 patients indicated that non-persistence with anti-osteoporosis drugs increased fracture risk by $32 \%$ (hazard ratio (HR) 1.32; $95 \%$ confidence interval (CI) 1.23-1.42) where follow-up between studies varied between 40 and 159 weeks [9]. The effectiveness of oral bisphosphonates in relation to duration of use was more specifically identified in a Dutch observational study; persistent use of oral bisphosphonates for 1-2 and 3-4 years reduced fracture risk by 12 and $46 \%$, respectively, compared to $<1$ year of use (OR 0.88, $95 \%$ CI $0.66-1.18$ and OR 0.54, $95 \%$ CI $0.35-0.84$, respectively) [12]. Real-world persistence with osteoporosis therapy is, however, poor. One-year persistence ranged from 18 to $78 \%$ between studies where differences were at least partly arising from non-uniformity used for the operational definition of persistence, including data-derived persistence and self-report [13-20].

While previous studies have been conducted among firsttime users of anti-osteoporosis drugs, there is a lack of understanding on fracture history with few studies identifying patients who had (recently) sustained an osteoporotic fracture. As a previous fracture is one of the most important risk factors for a subsequent fracture, it is important to investigate persistence with anti-osteoporosis drugs in this patient group and to understand its determinants. Furthermore, little is known about restart and subsequent persistence with these drugs after first discontinuation. Therefore, the aims of this study were (1) to identify long-term persistence with anti-osteoporosis drugs and its determinants in patients who had recently sustained a major osteoporotic fracture (hip, clinical vertebrae, humerus, forearm), (2) to determine the frequency of restarting treatment among patients who discontinued use, and (3) to assess persistence after restarting anti-osteoporosis treatment.

\section{Methods}

Data source

A cohort study was performed within the Dutch PHARMO Database Network [PHARMO Institute for Drug Outcome Research, www.pharmo.nl]. This data source contains primary care data linked to outpatient pharmacy dispensing data, hospitalizations from the Dutch Hospital Data Foundation (DHD, www.dutchhospitaldata.nl), and death registration data for approximately 660,000 communitydwelling individuals in the Netherlands. Almost every individual in the Netherlands is registered with a single community pharmacy, which results in a high degree of completeness with regard to dispensed drugs [21]. Drug-dispensing records contain information concerning the dispensed drug according to the Anatomical Therapeutic Chemical (ATC) Classification system codes including amount, dose, dosage regime, and date of dispensing. Primary care diagnoses are coded according to the International Classification of Primary Care (ICPC) coding system. Hospital records include dates of hospital admission and discharge, diagnoses, and procedures recorded according to the International Classification of Disease, 9th or 10th revision codes (ICD-9 or ICD-10).

\section{Study population}

All patients $\geq 50$ years with a first record of a hip, humerus, clinical vertebral, or forearm fracture since the start of data collection were identified. Fractures were extracted from primary care records and hospitalization data between 1 January 2002 and 31 December 2011. In the Netherlands, drugs available for the treatment of osteoporosis include bisphosphonates (alendronic acid, risedronic acid, etidronic acid, ibandronic acid, zoledronic acid), selective estrogen receptor modulators (SERMS; raloxifene, bazedoxifene), strontium ranelate, teriparatide, and denosumab. 
Patients were included at the date of first dispensing for an anti-osteoporosis drug in the year following the first fracture but not in the preceding year to include incident users only. The date of the first dispensing of an anti-osteoporosis drug after the fracture was set as the index date. Patients who were dispensed clodronic acid, pamidronic acid, tiludronic acid, or risedronic acid $30 \mathrm{mg}$ once daily were not included since these drugs are not registered for osteoporosis but for hypercalcemia during malignancy or Paget's disease, which may also increase fracture risk. In the Netherlands, repeated weekly dispensing of medications is an indicator of medication delivery by a "weekbox," suggesting that patient persistence is monitored by a health care professional, and thus, any discontinuation is likely not patient driven. To control for physician-directed discontinuation, patients with repeated weekly (7-day) dispensing records were excluded.

\section{Study outcomes}

The outcome of interest was persistence with any antiosteoporosis drug. Persistence was defined as the proportion of patients who were on treatment since treatment initiation [22]. Assessment of persistence was based on the calculation of the total duration of use where switching between drugs and dosage regimes was permitted [23]. The total duration of use was calculated on the basis of subsequent prescriptions for anti-osteoporosis drugs that were collected by (i.e., dispensed to) the patient at the community pharmacy. For each pharmacy dispensing, the theoretical duration of use was calculated by dividing the amount dispensed by the prescribed dosage regime. In the event of overlap between two dispensings (i.e., a repeat dispensing within the duration of use of a previous dispensing), the overlap days were added to the duration of the repeat dispensing. A gap of 90 days between the theoretical end date of a pharmacy dispensing (defined as the date of dispensing plus the theoretical duration of use) and the subsequent dispensing date was allowed. A patient was therefore classified as having discontinued with anti-osteoporosis treatment when either a gap of $>90$ days occurred between two dispensings, or when no further dispensing was issued and at least 90 days were available to the right censoring date. A 90-day permissible gap is consistent with prior literature [14, 15], and the maximum amount dispensed is a 90 days' supply in the Netherlands for chronic treatment, which is required for osteoporosis [23, 24]. In sensitivity analyses, permissible treatment gaps of 180, 270, and 365 days were applied.

Among patients who discontinued use using a 90-day permissible gap, the proportion restarting therapy was identified. Persistence with any anti-osteoporosis drug upon restart of therapy was determined similarly as described above.

\section{Definition of covariates}

Potential determinants of non-persistence (discontinuation) with anti-osteoporosis drugs were included in univariate and multivariate Cox proportional hazards models. Age, drug exposure, and comorbidities were included as time-dependent covariates. Total follow-up time was divided into 30-day intervals, and covariates were evaluated before each interval. Covariates included age groups (50-59, 60-69, 70-79, $\geq 80$ years), sex, type of fracture (hip, humerus, clinical vertebrae, forearm fracture), dosage regime of initial antiosteoporosis drug (daily, weekly, or monthly), drug use in the 6 months before (systemic glucocorticoids, antidepressants, non-selective anti-inflammatory drugs [NSAIDs], opioids [tramadol or stronger], calcium supplements and/or vitamin D, and disease-modifying anti-rheumatic drugs [DMARDs]), comorbidities included a diagnosis of dementia/Alzheimer's disease ever before, and the occurrence of upper gastrointestinal disorders or a subsequent fracture (at any site) in the 6 months before $[13,16,25]$. The presence of alcoholism was also considered, expressed by diagnosis codes for alcohol dependence and alcoholic liver diseases (alcoholic acute hepatitis, alcoholic liver cirrhosis, alcoholic liver damage, alcoholic fatty liver) or exposure to drugs for alcohol abstinence (disulfiram, acamprosate, nalmefene, naltrexone). An incident diagnosis of renal failure (diagnosis for renal failure or stage $4 / 5$ chronic kidney disease) was assessed but occurred too infrequent to include into the analysis $(n=3)$.

\section{Statistical analysis}

All patients were followed from the index date until discontinuation, death, migration out of the data source, or end of study period [31 December 2011], whichever came first. Kaplan-Meier life table analyses were used to present persistence estimates $(\%)$ over time where discontinuation was the failure event. Analyses were completed using the whole study population and stratified by age groups and type of index fracture. Log-rank tests were used to test for significant differences between groups. In addition, KaplanMeier life tables were applied to determine the cumulative incidence of restarting any anti-osteoporosis drug after first 90-day discontinuation.

Determinants of non-persistence were estimated by timedependent Cox proportional hazards regression (PHREG procedure) by entering all covariates into the regression model. The proportional hazards assumption was tested by including time interaction terms into the model. In case of violation ( $p$ value interaction $<0.05$ ), hazard ratios for the association between that covariate and non-persistence were calculated for two periods by restricting follow-up time to the first 12 30-day periods and the period thereafter $(\leq 360$ and 
$>360$ days), to present the hazard ratio for "early" and

"late" discontinuation, respectively.

All statistical analyses were performed using SAS statistical software, version 9.2 (SAS Institute, Inc., Cary, NC, USA).

\section{Results}

A total of 1081 patients were identified as incident users of anti-osteoporosis drugs within 1 year after the first fracture. Of these, 120 patients had repeated 7-day dispensing indicating "weekbox" dispensing and were excluded. The final study cohort included 961 patients $(81.3 \%$ female) with a mean age of 69.8 years ( $\mathrm{SD}=9.6$ years). The vast majority initially received a bisphosphonate $(96.5 \%)$, most frequently alendronic acid $(67.3 \%)$ or risedronic acid (29.7\%). Alternatives for bisphosphonates, such as raloxifene and strontium ranelate, were rarely dispensed (Table 1). During follow-up, a total of 89 (9.3\%) patients switched between types of anti-osteoporosis drugs, where $67.4 \%$ of all switches occurred between alendronic acid and risedronic acid. Bisphosphonates were predominantly prescribed in a weekly dosage regime (94.2\%). Of patients initiating on a daily dosage, $36.4 \%$ switched to another dosage regime during follow-up.

Persistence estimates for treatment with anti-osteoporosis drugs are displayed in Fig. 1a for the total study population. Persistence decreased from $75.0 \%$ (95\% CI 72.0-77.7) at 1 year to $45.3 \%$ (95\% CI 40.4-50.0) at 5 years following initiation. The median time on treatment was 4.6 years [95\% CI 4.1-5.0]. Increasing the gap length showed increases in persistence (Table 2). When stratified by age groups, significant differences in persistence were identified $(p=0.003)$, with those aged 80 years and older at index date having the lowest persistence (Fig. 1b), but no significant difference was noted between fracture types $(p=0.17)$ (Fig. 1c). Of those aged 80 years and older, $63.9 \%$ (95\% CI 55.8-70.9) persisted for 1 year following treatment initiation, as compared to $82.8 \%$ (95 \% CI 75.7-88.0) of those aged 50-59 years.

Table 3 presents associations between the covariates and non-persistence with anti-osteoporosis drugs. In a multivariate model, age $\geq 80$ years was identified as a significant determinant of discontinuation (reference 50-59 years; adjusted [adj.] hazard ratio [HR] 1.65; $95 \%$ CI 1.15-2.38). The effect of age, however, was not constant over time ( $p$ value interaction $<0.05$ ). When follow-up was restricted to the first 360 days following initiation, persistence was significantly lower for those $\geq 80$ years as compared to those $50-59$ years (adj. HR 2.07 ; $95 \%$ CI 1.27-3.37), while this was not observed beyond 360 days of follow-up (adj. HR 1.08; 0.62-1.88). The association between an initial daily versus weekly dosage regime and non-persistence was also not constant over time ( $\leq 360$ days; adj. HR 1.49, $95 \%$ CI 0.95-2.35, >360 days;
Table 1 Characteristics of new anti-osteoporosis drug users who sustained a recent fracture

\begin{tabular}{|c|c|}
\hline Characteristics & $N=961$ \\
\hline Follow-up time, mean (SD), years & $3.0(2.1)$ \\
\hline Female sex & $781(81.3 \%)$ \\
\hline Age, mean (SD), years & $69.8(9.6)$ \\
\hline \multicolumn{2}{|l|}{ Age categories } \\
\hline $50-59$ & $161(16.8 \%)$ \\
\hline $60-69$ & $308(32.0 \%)$ \\
\hline $70-79$ & $322(33.5 \%)$ \\
\hline$\geq 80$ & $170(17.7 \%)$ \\
\hline \multicolumn{2}{|l|}{ Type of index fracture } \\
\hline Hip & $204(21.2 \%)$ \\
\hline Humerus & $127(13.2 \%)$ \\
\hline Clinical vertebral & $322(33.5 \%)$ \\
\hline Forearm & $308(32.0 \%)$ \\
\hline \multicolumn{2}{|l|}{ Initial anti-osteoporosis drug } \\
\hline Bisphosphonate & $927(96.5 \%)$ \\
\hline Alendronic acid & $624(67.3 \%)$ \\
\hline Risedronic acid & $275(29.7 \%)$ \\
\hline Other bisphosphonate $^{\mathrm{a}}$ & $28(3.0 \%)$ \\
\hline Strontium ranelate & $29(3.0 \%)$ \\
\hline Other $^{\mathrm{b}}$ & $5(0.5 \%)$ \\
\hline \multicolumn{2}{|l|}{ Dosage regime } \\
\hline Daily & $67(7.0 \%)$ \\
\hline Weekly & $873(90.8 \%)$ \\
\hline Monthly & $21(2.2 \%)$ \\
\hline \multicolumn{2}{|l|}{ Diseases } \\
\hline $\begin{array}{l}\text { Upper gastrointestinal disorders } 6 \text { months before } \\
\text { index date }^{c}\end{array}$ & $26(2.7 \%)$ \\
\hline $\begin{array}{l}\text { Dementia/Alzheimer's disease ever before index } \\
\text { date }^{c} \text { and during follow-up }\end{array}$ & $25(2.6 \%)$ \\
\hline $\begin{array}{l}\text { Alcoholism ever before index date }{ }^{\mathrm{c}} \text { and during } \\
\text { follow-up }\end{array}$ & $24(2.5 \%)$ \\
\hline Fracture at any site during follow-up & $80(8.3 \%)$ \\
\hline Upper gastrointestinal disorders during follow-up & $74(7.7 \%)$ \\
\hline \multicolumn{2}{|l|}{ Drug use during 6 months before index date ${ }^{\mathrm{c}}$} \\
\hline Systemic glucocorticoids & $78(8.1 \%)$ \\
\hline Antidepressants & $92(9.6 \%)$ \\
\hline Opioids (tramadol or stronger) & $97(10.1 \%)$ \\
\hline Non-steroidal anti-inflammatory drugs & $347(36.1 \%)$ \\
\hline Calcium-supplements and/or vitamin D & $64(6.7 \%)$ \\
\hline Disease-modifying anti-rheumatic drugs & $13(1.4 \%)$ \\
\hline \multicolumn{2}{|l|}{${ }^{\mathrm{a}}$ Etidronic acid, ibandronic acid } \\
\hline $\begin{array}{l}{ }^{\mathrm{c}} \text { Index date defined as date of first dispensing for a } \\
\text { drug within } 1 \text { year after fracture }\end{array}$ & osteop \\
\hline
\end{tabular}

adj. HR $0.68 ; 95 \%$ CI $0.35-1.30, p$ value interaction $<0.05$ ). Sensitivity analyses with increasing gap lengths provided similar results, where age $\geq 80$ years remained the only 
(a)

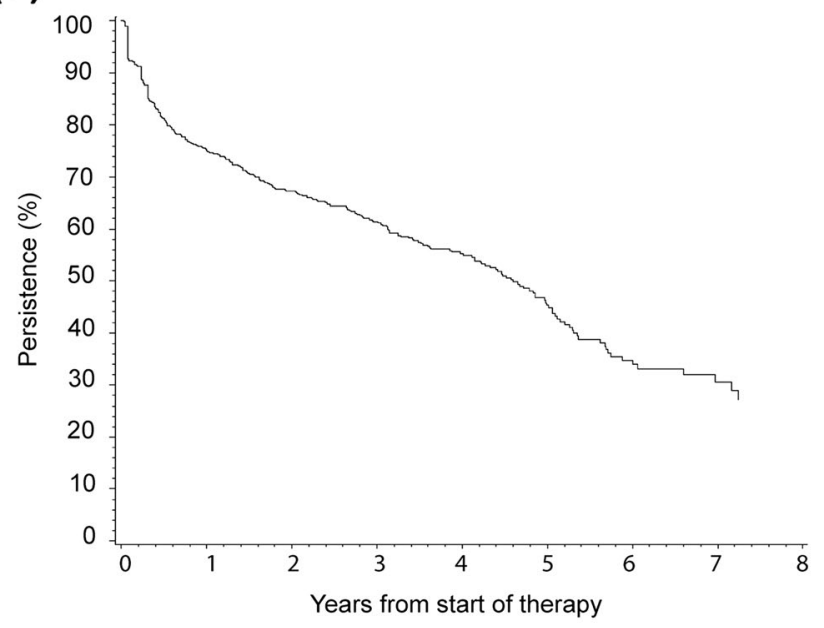

(b)

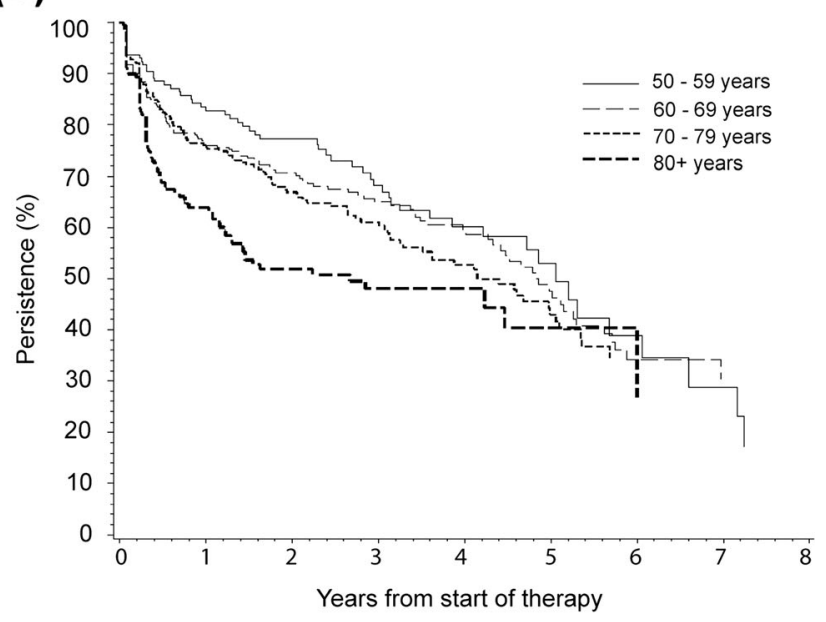

(c)

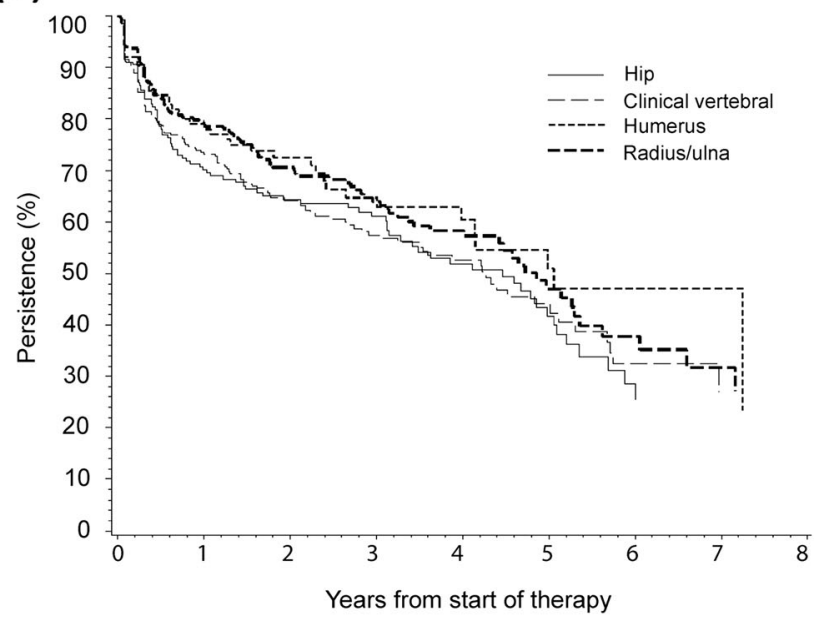

Fig. 1 Kaplan-Meier persistence curves for treatment with antiosteoporosis drugs after a recent fracture for a the total study population, b stratified by age category, $\mathbf{c}$ stratified by type of fracture - discontinuation was defined as a treatment gap of $>90$ days and switching between anti-osteoporosis drugs or dosage regimes was allowed when this occurred within the treatment gap
Table 2 Kaplan-Meier estimates for persistence (\%) at different time periods following initiation, by gap length

\begin{tabular}{clll}
\hline \multicolumn{4}{c}{ Survival time } \\
\cline { 2 - 4 } & 1 year & 3 years & 5 years \\
\hline Gap length & & & \\
90 days & $75.0(72.0-77.7)$ & $61.3(57.6-64.8)$ & $45.3(40.4-50.0)$ \\
180 days & $79.2(76.3-81.7)$ & $68.2(64.7-71.5)$ & $53.6(48.6-58.4)$ \\
270 days & $82.2(79.5-84.6)$ & $73.0(69.6-76.1)$ & $58.9(53.7-63.6)$ \\
365 days & $84.4(81.9-86.6)$ & $75.2(71.9-78.3)$ & $64.4(59.5-68.9)$ \\
\hline
\end{tabular}

Patients were followed until first date of the following: discontinuation (non-persistence), death, migration out of data source, or end of study period

significant determinant of non-persistence (see supplementary Table S1/S2/S3).

Figure 2 shows the cumulative incidence of restarting any anti-osteoporosis drug after first discontinuation. Of all patients who discontinued treatment, $24.3 \%(95 \% \mathrm{CI}$ 20.1-29.2) restarted therapy within 1 year, and this increased to $40.4 \%$ (95\% CI 32.4-49.4) within 5 years. Patients who discontinued treatment were less likely to stay on treatment after restart; $47.0 \%$ (95 \% CI 36.4-56.9) persisted for 1 year. The median time on treatment was 0.92 years (95\% CI 0.61-1.47) (Fig. 3).

\section{Discussion}

In this cohort of newly treated fracture patients, persistence with anti-osteoporosis drugs decreased from $75 \%$ at 1 year to $45 \%$ at 5 years following initiation. Patients aged 80 years and older were at increased risk of early discontinuation. A substantial proportion of patients restarted treatment following first discontinuation; yet, $47 \%$ persisted with treatment for 1 year following restarting therapy.

Persistence estimates were higher than expected when compared to previously conducted studies among first-time users who did not initiate treatment specifically after fracture. A meta-analysis showed a pooled persistence estimate of $50 \%$ (95\% CI 37-63\%) for treatment lasting 7 to 12 months as measured by treatment gaps that ranged from 30 to 120 days [19]. They also found increased persistence among patients allowed to switch medications (58 \% [95\% CI 45-70\%) vs $46 \%$ [95\% CI 38-55\%]). Another study that was conducted among new users irrespectively of fracture status and that similarly defined persistence as the present study (90-day gap and allowed switching between drugs) found a 1-year persistence estimate of $67 \%$ (95\% CI 66-68), which was still lower as compared to the current study [15]. This suggests that the setting, where treatment was initiated after a recent 
Table 3 Determinants of nonpersistence ( $>90$-day gap) with anti-osteoporosis drugs after fracture

$\mathrm{Cr}$ crude, $A d j$ adjusted, $H R$ hazard ratio, $95 \%$ CI $95 \%$ confidence interval

${ }^{a}$ Reference group is no use within 6 months prior within that drug category

${ }^{\mathrm{b}}$ Reference group is no occurrence within 6 months prior (ever prior for dementia/Alzheimer's disease or alcoholism) within that disease category

\begin{tabular}{|c|c|c|}
\hline & Cr. HR (95 \% CI) & Adj. HR $(95 \% \mathrm{CI})$ \\
\hline \multicolumn{3}{|l|}{ Gender } \\
\hline Male & Reference & Reference \\
\hline Female & $0.91(0.71-1.18)$ & $0.97(0.74-1.26)$ \\
\hline \multicolumn{3}{|l|}{ Age categories } \\
\hline $50-59$ years & Reference & Reference \\
\hline $60-69$ years & $1.05(0.75-1.47)$ & $1.06(0.76-1.50)$ \\
\hline $70-79$ years & $1.15(0.82-1.60)$ & $1.13(0.80-1.58)$ \\
\hline$\geq 80$ years & $1.70(1.20-2.42)$ & $1.65(1.15-2.38)$ \\
\hline \multicolumn{3}{|l|}{ Type of index fracture } \\
\hline Forearm & Reference & Reference \\
\hline Humerus & $0.92(0.65-1.31)$ & $0.87(0.61-1.24)$ \\
\hline Clinical vertebral & $1.22(0.95-1.57)$ & $1.13(0.87-1.47)$ \\
\hline Hip & $1.24(0.94-1.63)$ & $1.08(0.81-1.44)$ \\
\hline \multicolumn{3}{|l|}{ Dosage regime } \\
\hline Once daily & $1.21(0.84-1.74)$ & $1.06(0.73-1.54)$ \\
\hline Once weekly & Reference & Reference \\
\hline Once monthly & $0.58(0.24-1.40)$ & $0.58(0.24-1.41)$ \\
\hline \multicolumn{3}{|l|}{ Drug use $^{\mathrm{a}}$} \\
\hline Systemic glucocorticoids & $1.21(0.84-1.73)$ & $1.18(0.82-1.70)$ \\
\hline Antidepressants & $1.12(0.81-1.55)$ & $1.11(0.80-1.54)$ \\
\hline Opioids (tramadol or stronger) & $1.00(0.65-1.53)$ & $0.83(0.53-1.29)$ \\
\hline Non-steroidal anti-inflammatory drugs & $1.01(0.79-1.31)$ & $0.98(0.76-1.27)$ \\
\hline Calcium supplements and/or vitamin D & $0.96(0.77-1.19)$ & $0.94(0.76-1.17)$ \\
\hline Disease-modifying anti-rheumatic drugs & $1.01(0.48-2.14)$ & $1.10(0.52-2.34)$ \\
\hline \multicolumn{3}{|l|}{ Disease occurrence $^{\mathrm{b}}$} \\
\hline Dementia/Alzheimer's disease & $1.71(0.94-3.11)$ & $1.46(0.79-2.70)$ \\
\hline Subsequent fractures & $1.70(0.91-3.21)$ & $1.64(0.86-3.10)$ \\
\hline Upper gastrointestinal disorders & $1.54(0.79-3.00)$ & $1.40(0.71-2.74)$ \\
\hline Alcoholism & $1.55(0.80-3.01)$ & $1.50(0.76-2.96)$ \\
\hline
\end{tabular}

fracture, may have influenced persistence. Indeed, studies that included patients who visited fracture liaison services (FLSs) showed 1-year persistence that ranged between 74 and $88 \%$, which were either based on self-report [25-28] or prescription claims [29]. These numbers may, however, have been biased upward by selection toward more motivated patients as only patients agreeing to participate in FLSs were included (response rate ranged between 38 and $88 \%$ ). To the best of our knowledge, the only previously conducted population-based study that assessed persistence after fracture (1997-2004) showed a 1-year persistence estimate of $80 \%$ with alendronic acid weekly, etidronic acid, or raloxifene [30].

In a multivariable adjusted analysis, age of 80 years and older (reference 50-59 years) was identified as a significant determinant of non-persistence with anti-osteoporosis drugs early after initiation. This finding is in line with the, to the best of our knowledge, only previous study that explored determinants of non-persistence with these drugs when initiated after recent fracture (OR 1.008; $95 \%$ CI 1.004-1.012 per year of age) [30]. Although older age was identified as a marker for increased risk of early discontinuation, the underlying reasons remain unknown and may be multifactorial, including but not limited to the number of comorbid conditions, poly-pharmacy, physical inability or dependency of others to take medication, or willingness to take medication.

A weekly dosage regime has now been widely adopted in clinical practice and has been associated with increased persistence when compared to a daily regime although evidence is conflicting for the difference in persistence between weekly and monthly regimes $[13,17]$. In the present study, we did not find evidence that daily and monthly dosage regimes of the initial drug were associated with increased or decreased risk of discontinuation compared to a weekly regime, respectively. However, switching between anti-osteoporosis drugs and dosage regimes was permitted and may have diluted the association. In addition, the number of daily and monthly users was limited (daily, $7 \%$ of whom $3.4 \%$ were daily bisphosphonate users; monthly, $2.2 \%$ ). Similarly, the occurrence of upper 


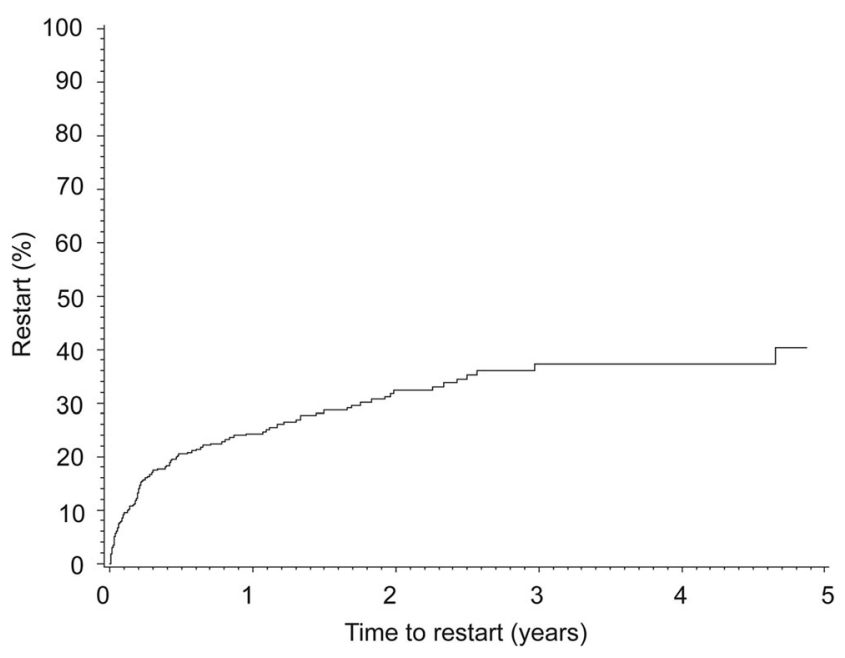

Fig. 2 Kaplan-Meier curve for cumulative incidence of restart with antiosteoporosis drugs after first discontinuation ( $>90$-day gap)

gastrointestinal disorders is a frequently cited reason for discontinuation of bisphosphonates, but this was not confirmed in the present study [31-33]. Again, switching between antiosteoporosis drugs was allowed and may explain this finding. Furthermore, a qualitative study indicated that fear for side effects, while they did not occur yet, was enough to discontinue with treatment, which was not captured in our data [26].

Approximately $40 \%$ of patients restarted therapy within 5 years after discontinuation, of whom the majority did so within the first 6 months. Previous studies showed proportions of restarting patients varying between 18 and $38 \%$ within 6 months after first discontinuation [13, 18, 34-36]. Our finding of $20 \%$ is at the lower end of this range and is in agreement with a Dutch study, where $18 \%$ of osteoporotic patients restarted therapy within 6 months [13]. The substantial proportion of patients who restarted therapy was reflected by an increase in persistence over time when permissible treatment gaps became wider. The present study identified that

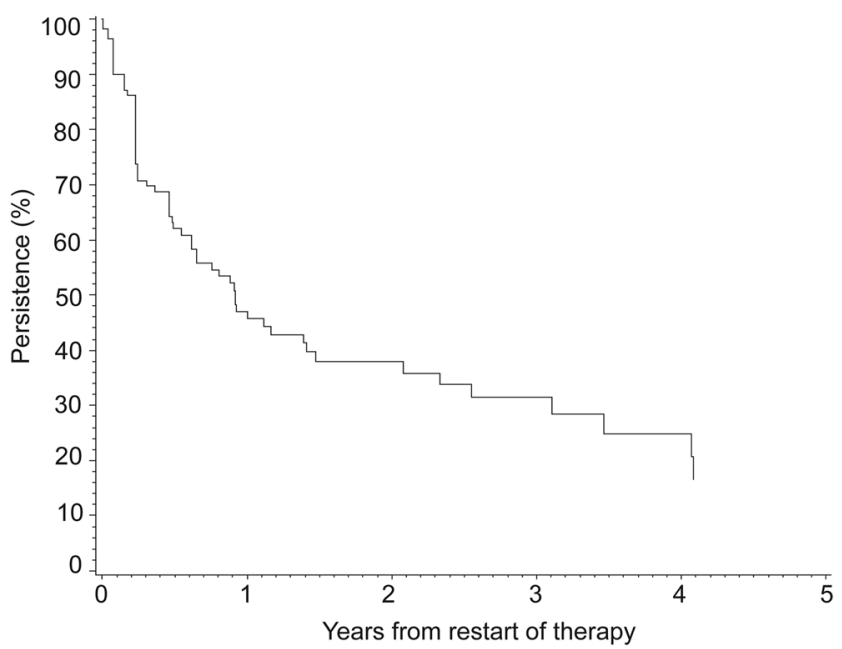

Fig. 3 Kaplan-Meier persistence curve for treatment with antiosteoporosis drugs following restart of therapy ( $>90$-day gap) persistence with anti-osteoporosis therapy was poor among restarting patients. While there is little evidence of persistence after restarting therapy, the results of this study are similar to, to our knowledge, the only previous study to address this issue, which identified a median duration of persistence of 6 months following restart (>60-day gap) [18].

Strengths of this study include that persistence was determined over a long-term follow-up period and that linkage of longitudinal data of hospitalizations, diagnoses made by general practitioners, mortality, and drug dispensing was possible. The majority of studies on anti-osteoporosis drug persistence included a short 1-year follow-up with a focus on first treatment discontinuation. However, determining persistence for the initial drug or first treatment period may result in an underestimation of total exposure. Indeed, this study identified that up to a quarter of patients who discontinued therapy returned to treatment within 1 year of discontinuation which increased to $40 \%$ within 5 years. Although it is encouraging that many patients may return to therapy, extended gaps in therapy may result in reduced effectiveness. This may, however, depend on the duration of prior exposure as limited evidence shows a residual anti-fracture effect during posttreatment follow-up that was inversely associated with time on treatment and may be explained by accumulation of bisphosphonates in the bone [37].

A limitation of this study was that persistence relied on pharmacy dispensing data where the actual intake remained unknown. However, several studies showed that repeated dispensing records are a good indicator of consumptions [38, 39]. Second, due to the coding system within general practitioner records, we were not able to disentangle proximal humerus fractures from those of the distal part and shaft. Proximal humerus fractures have been associated with osteoporotic BMD [40, 41] and fracture risk [40], while little is known for those of the shaft and distal part where benefits of treatment with anti-osteoporosis drugs may be less clear. We believe that the impact of this is limited as proximal humerus fractures are the dominant type of humerus fractures after the age of 50 years [42] and the study population was highly likely to have osteoporotic BMD since the Dutch primary care guideline primarily focusses on DXA-diagnosed osteoporosis when considering starting anti-osteoporosis drugs after nonvertebral fractures. Furthermore, this study only identified old age as a significant determinant of discontinuation and the results of several other determinants, including dementia, exposure to DMARDs, initial monthly dosage regime, and alcohol-related diagnoses, should be interpreted with caution due to the low numbers of patients exposed. An incident diagnosis of renal failure may as well be a determinant of discontinuation but could not be included in the analyses due to the fact that only three patients with this determinant were present. Another limitation was that intravenously administered anti-osteoporosis drugs (zoledronic acid) or 
subcutaneous drugs (e.g., teriparatide, denosumab) prescribed by a specialist were not (completely) captured as they are either delivered to the patient in the hospital or frequently by special ambulatory pharmacies. A significant underestimation of persistence due to this limitation, however, is unlikely as zoledronic acid was not frequently administered during the study period [43], denosumab was introduced in the Netherlands in the year 2011, and teriparatide is only reimbursed under restricted conditions.

In conclusion, results identified suboptimal persistence among a cohort of patients with prior fracture, highlighting the need for additional research focused on improving persistence among patients at high risk for subsequent fractures, which includes a better understanding of the underlying reasons for non-persistence. The results of the present study further add to the literature by identifying the frequency of treatment re-initiation following an extended gap and the subsequent persistence with therapy. There are a number of opportunities for improving treatment persistence, including educational interventions targeted at physicians and/or patients as many physicians may be unaware of, and therefore unable to address, non-adherence [44, 45] and both physicians as patients may be sceptical or unaware of treatment benefits, other opportunities include telephone-based counselling [46], pharmaceutical intervention [47, 48], or use of patient decision aids [49]; yet, few have proven effective in clinical settings [50]. Major target groups for intervention after a recent fracture may be those aged 80 or more years and those restarting therapy following an extended gap.

Acknowledgments This study was supported by a research grant from The Netherlands Organization for Health Research and Development [ZonMw; grant number 113101007].

Conflicts of interest The Division of Pharmacoepidemiology and Clinical Pharmacology employing CK, FV, PCS, AMB has received unrestricted funding from the Netherlands Organisation for Health Research and Development (ZonMW), the Dutch Health Care Insurance Board (CVZ), the Royal Dutch Pharmacists Association (KNMP), the private-public funded Top Institute Pharma (www.tipharma.nl), includes co-funding from universities, government, and industry), the EU Innovative Medicines Initiative (IMI), the EU 7th Framework Program (FP7), the Dutch Ministry of Health and industry (including GlaxoSmithKline, Pfizer, and others); HGML is a researcher at The WHO Collaborating Centre for Pharmaceutical Policy and Regulation, which receives no direct funding or donations from private parties, including pharma industry. Research funding from public-private partnerships, e.g., IMI, TI Pharma (www.tipharma.nl) is accepted under the condition that no company-specific product or company-related study is conducted. The Centre has received unrestricted research funding from public sources, e.g., Netherlands Organisation for Health Research and Development (ZonMW), the Dutch Health Care Insurance Board (CVZ), EU 7th Framework Program (FP7), Dutch Medicines Evaluation Board (MEB), and Dutch Ministry of Health; JO is an employee of the PHARMO Institute. This independent research institute performs financially supported studies for government and related healthcare authorities and several pharmaceutical companies. AMB is supported by a Canadian Institutes of Health Research (CIHR) Post Doctoral Fellowship. The funders had no role in study design, data collection and analysis, interpretation of the data, decision to publish, or preparation of the manuscript.

The authors PMJW, PJME, HAWvO, and JWJB declare that they have no conflict of interest.

Open Access This article is distributed under the terms of the Creative Commons Attribution Noncommercial License which permits any noncommercial use, distribution, and reproduction in any medium, provided the original author(s) and the source are credited.

\section{References}

1. Kanis JA, Johnell O (1999) The burden of osteoporosis. J Endocrinol Investig 22:583-588

2. Lindsay R, Silverman SL, Cooper C, Hanley DA, Barton I, Broy SB et al (2001) Risk of new vertebral fracture in the year following a fracture. JAMA 285:320-323

3. Van Geel TA, van Helden S, Geusens PP, Winkens B, Dinant GJ (2009) Clinical subsequent fractures cluster in time after first fractures. Ann Rheum Dis 68:99-102

4. Huntjens KMB, Kosar S, van Geel TACM, Geusens PP, Willems P, Kessels A et al (2010) Risk of subsequent fracture and mortality within 5 years after a non-vertebral fracture. Osteoporos Int 21: 2075-2082

5. Gibson-Smith D, Klop C, Elders PJ, Welsing PM, van Schoor N, Leufkens HG et al (2014) The risk of major and any (non-hip) fragility fracture after hip fracture in the United Kingdom: 2000-2010. Osteoporos Int 25:2555-2563

6. Wells GA, Cranney A, Peterson J, Boucher M, Shea B, Robinson V et al (2008) Alendronate for the primary and secondary prevention of osteoporotic fractures in postmenopausal women. Cochrane Database Syst Rev 1, CD001155

7. Wells GA, Cranney A, Peterson J, Boucher M, Shea B, Robinson V et al (2008) Risedronate for the primary and secondary prevention of osteoporotic fractures in postmenopausal women. Cochrane Database Syst Rev 1, CD004523

8. National Institute for Health and Clinical Excellence (NICE) (2008) Systematic reviews of clinical effectiveness prepared for the guideline 'Osteoporosis: assessment of fracture risk and the prevention of osteoporotic fractures in individuals at high risk'.https://www.nice. org.uk/guidance/cg146/documents/osteoporosis-evidence-reviews2. Accessed 16 Sept 2014

9. Ross S, Samuels E, Gairy K, Iqbal S, Badamgaray E, Siris E (2011) A meta-analysis of osteoporotic fracture risk with medication nonadherence. Value Health 14:571-581

10. Hadji P, Claus V, Ziller V, Intorcia M, Kostev K, Steinle T (2012) GRAND: the German retrospective cohort analysis on compliance and persistence and the associated risk of fractures in osteoporotic women treated with oral bisphosphonates. Osteoporos Int 23:223-31

11. Sampalis JS, Adachi JD, Rampakakis E, Vaillancourt J, Karellis A, Kindundu C (2012) Long-term impact of adherence to oral bisphosphonates on osteoporotic fracture incidence. J Bone Miner Res 27:202-10

12. Meijer WM, Penning-van Beest FJA, Olson M, Herings RMC (2008) Relationship between duration of compliant bisphosphonate use and the risk of osteoporotic fractures. Curr Med Res Opin 24:3217-3222

13. Netelenbos JC, Geusens PP, Ypma G, Buijs SJE (2011) Adherence and profile of non-persistence in patients treated for osteoporosis - a large-scale, long-term retrospective study in the Netherlands. Osteoporos Int 22:1537-46 
14. Li L, Roddam A, Gitlin M, Taylor A, Shepherd S, Shearer A et al (2012) Persistence with osteoporosis medications among postmenopausal women in the UK General Practice Research Database. Menopause 19:33-40

15. Van Boven JFM, de Boer PT, Postma MJ, Vegter S (2013) Persistence with osteoporosis medication among newly-treated osteoporotic patients. J Bone Miner Metab 31:562-570

16. Penning-van Beest FJA, Goettsch WG, Erkens JA, Herings RMC (2006) Determinants of persistence with bisphosphonates: a study in women with postmenopausal osteoporosis. Clin Ther 28:236-42

17. Confavreux CB, Canoui-Poitrine F, Schott A, Ambrosi V, Tainturier V, Chapurlat RD (2012) Persistence at 1 year of oral antiosteoporitic drugs: a prospective study in a comprehensive health insurance database. Eur J Endocrinol 166:735-741

18. Balasubramanian A, Brookhart MA, Goli V, Critchlow CW (2013) Discontinuation and reinitiation patterns of osteoporosis treatment among commercially insured postmenopausal women. Int J Gen Med 6:839-848

19. Kothawala P, Badamgarav E, Ryu S, Miller RM, Halbert RJ (2007) Systematic review and meta-analysis of real-world adherence to drug therapy for osteoporosis. Mayo Clin Proc 82:1493-501. doi:10.1016/ S0025-6196(11)61093-8

20. Cramer JA, Gold DT, Silverman SL, Lewiecki EM (2007) A systematic review of persistence and compliance with bisphosphonates for osteoporosis. Osteoporos Int 18:1023-31. doi:10.1007/s00198-0060322-8

21. Buurma H, Bouvy ML, De Smet PA, Floor-Schreudering A, Leufkens HG, Egberts AC (2008) Prevalence and determinants of pharmacy shopping behavior. J Clin Pharm Ther 33:17-23

22. Vrijens B, De Geest S, Hughes DA, Przemyslaw K, Demonceau J, Ruppar T et al (2012) A new taxonomy for describing and defining adherence to medications. Br J Clin Pharmacol 73:691-705

23. Gardarsdottir H, Souverein PC, Egberts TCG, Heerdink ER (2010) Construction of drug treatment episodes from drug-dispensing histories is influenced by the gap length. J Clin Epidemiol 63:422-427

24. Geers HC, Bouvy ML, Heerdink ER (2011) Estimates of statin discontinuation rates are influenced by exposure and outcome definitions. Ann Pharmacother 45:576-81

25. Eekman DA, van Helden H, Huisman AM, Verhaar HJJ, Bultink IEM, Geusens PP et al (2013) Optimizing fracture prevention: the fracture liaison service, an observational study. Osteoporos Int. doi: 10.1007/s00198-013-2481-8

26. Boudou L, Gerbay B, Chopin F, Ollagnier E, Collet P, Thomas T (2011) Management of osteoporosis in fracture liaison service associated with long-term adherence to treatment. Osteoporos Int 22: 2099-2106

27. Ojeda-Bruno S, Naranjo A, Francisco-Hernández F, Erausquin C, Rúa-Figueroa I, Ouevedo C et al (2011) Secondary prevention program for osteoporotic fractures and long-term adherence to bisphosphonates. Osteoporos Int 22:1821-1828

28. Dehamchia-Rehailia N, Ursu D, Henry-Desailly I, Fardellone P, Paccou J (2014) Secondary prevention of osteoporotic fractures: evaluation of the Amiens University Hospital's fracture liaison service between January 2010 and December 2011. Osteoporos Int 25: 2409-2416

29. Ganda K, Schaffer A, Pearson S, Seibel MJ (2014) Compliance and persistence to oral bisphosphonate therapy following initiation within a secondary fracture prevention program: a randomised controlled trial of specialist vs. non-specialist management. Osteoporos Int 25: $1345-1355$

30. Roerholt C, Eiken P, Abrahamsen B (2009) Initiation of antiosteoporotic therapy in patients with recent fractures: a nationwide analysis of prescription rates and persistence. Osteoporos Int 20:299-307

31. Sewerynek E, Horst-Sikorska H, Stepien-Klos W, Antkowiak A, Janik M, Cieslak K et al (2013) The role of counseling and other factors in compliance of postmenopausal osteoporotic patients to alendronate 70 therapy. Arch Med Sci 9:288-296

32. McHorney CA, Schousboe JT, Cline RR, Weiss TW (2007) The impact of osteoporosis medication beliefs and side-effect experiences on non-adherence to oral bisphosphonates. Curr Med Res Opin 23: 3137-3152

33. Salter C, McDaid L, Bhattacharya D, Holland R, Marshall T, Howe A (2014) Abandoned acid? Understanding adherence to bisphosphonate medications for the prevention of osteoporosis among older women: a qualitative longitudinal study. PLoS ONE 9:e83552. doi: 10.1371/journal.pone.0083552

34. Brookhart MA, Avorn J, Katz JN, Finkelstein JS, Arnold M, Polinski JM et al (2007) Gaps in treatment among users of osteoporosis medications: the dynamics of noncompliance. Am J Med 120:251-6

35. Lo JC, Pressman AR, Omar MA, Ettinger B (2006) Persistence with weekly alendronate therapy among postmenopausal women. Osteoporos Int 17:922-928

36. Burden AM, Paterson JM, Solomon DH, Mamdani M, Juurlink DN, Cadarette SM (2012) Bisphosphonate prescribing, persistence and cumulative exposure in Ontario, Canada. Osteoporos Int 23:107582. doi:10.1007/s00198-011-1645-7

37. Ström O, Landfeldt E, Garellick G (2015) Residual effect after oral bisphosphonate treatment and healthy adherer effects-the Swedish adherence register analysis (SARA). Osteoporos Int 26:315-325

38. Grymonpre R, Cheang M, Fraser M, Metge C, Sitar DS (2006) Validity of a prescription claims database to estimate medication adherence in older persons. Med Care 44:471-477

39. Lau HS, de Boer A, Beuning KS, Porsius A (1997) Validation of pharmacy records in drug exposure assessment. J Clin Epidemiol 50:619-625

40. Morin SN, Lix LM, Leslie WD (2014) The importance of previous fracture site on osteoporosis diagnosis and incident fractures in women. J Bone Miner Res 29:1675-1680

41. Schuit SC, van der Klift M, Weel AE, de Laet CE, Burger H, Seeman $E$ et al (2004) Fracture incidence and association with bone mineral density in elderly men and women: the Rotterdam Study. Bone 34: 195-202

42. Kim SH, Szabo RM, Marder RA (2008) Epidemiology of humerus fractures in the United States: nationwide emergency department sample. Arthritis Care Res 64:407-414

43. Peeters G, Tett SE, Duncan EL, Mishra GD, Dobson AJ (2014) Osteoporosis medication dispensing for older Australian women from 2002 to 2010: influences of publications, guidelines, marketing activities and policy. Pharmacoepidemiol Drug Saf. doi:10.1002/pds. 3703

44. Curtis JR, Cai Q, Wade SW, Stolshek BS, Adams JL, Balasubramanian A et al (2013) Osteoporosis medication adherence: physician perceptions vs. patient's utilization. Bone 55:1-6

45. Shu AD, Stedman MR, Polinski JM, Jan SA, Patel M, Truppo C et al (2009) Adherence to osteoporosis medications after patient and physician brief education: post hoc analysis of a randomized controlled trial. Am J Manage Care 15:417-424

46. Solomon DH, Iversen MD, Avorn J, Gleeson T, Brookhart MA, Patrick AR et al (2012) Osteoporosis telephonic intervention to improve medication regimen adherence. A large, pragmatic, randomized controlled trial. Arch Intern Med 172:477-483

47. Stuurman-Bieze AGG, Hiddink EG, van Boven JFM, Vegter S (2014) Proactive pharmaceutical care interventions decrease patient's nonadherence to osteoporosis medication. Osteoporos Int 25:18071812

48. Van Boven JFM, Hiddink EG, Stuurman-Bieze AGG, Postma MJ, Vegter S (2011) Gestructureerde medicatiebegeleiding om de therapietrouw bij bisphosphonaten te verbeteren biedt kansen voor kosteneffectieve farmaceutische patientenzorg. PW Wetenschappelijk Platform 5:a1132 
49. Montori VM, Shah ND, Pencille LJ, Branda ME, van Houten HK, Swiglo BA et al (2011) Use of a decision aid to improve treatment decisions in osteoporosis: the osteoporosis choice randomized trial. Am J Med 124:549-556
50. Hiligsmann M, Salas M, Hughes DA, Manias E, Gwadry-Sridhar FH, Linck P et al (2013) Interventions to improve osteoporosis medication adherence and persistence: a systematic review and literature appraisal by the ISPOR Medication Adherence \& Persistence Special Interest Group. Osteoporos Int 24:2907-2918 